\title{
A nonassociative aspect of overshadowing
}

\author{
MARK A. KAUFMAN and ROBERT C. BOLLES \\ University of Washington, Seattle, Washington 98195
}

\begin{abstract}
A light overshadowed a noise in a conditioned fear paradigm. There was less fear of the noise if it had been compounded with the light when paired with shock than if the noise alone had been paired with shock. However, a high level of fear to the noise was found in rats that subsequently underwent extinction of the fear conditioned to the light. This finding suggests that overshadowing is not due just to the noise not being associated with shock; it suggests that overshadowing is due in part to a failure of the noise-shock association to be expressed in behavior.
\end{abstract}

If conditioning is carried out with a compound CS, for example, a bright light and a soft tone, it is generally found that a lot of conditioning occurs to the bright light but very little occurs to the soft tone. The light is then said to overshadow the tone. Overshadowing has been long recognized (Pavlov, 1927) and well documented (Mackintosh, 1974), but it is not very well understood. One simple ready account of it is based on the idea that the bright light is more salient than the soft tone; it is simply a more effective CS. There are, however, two difficulties with this easy explanation. One is that it fails to deal with the fact that the soft tone, if presented alone, may prove to be a quite adequate CS. This fact, first noted by Pavlov and also now well documented, indicates that overshadowing must be due, at least in some part, to some kind of competitive process. The presence of the bright light interferes in some way with the conditioning that would otherwise occur to the weak tone. The interference might be associative, that is, it might result from the competition between the two associations, or it might be due to some kind of nonassociative selection process, such as attention.

The second problem with the salience argument is that it is easy to find overshadowing when the dominant stimulus has a quite modest intensity. James and Wagner (1980) reported that a seemingly weak light could overshadow a rather loud tone, and we will report the same effect here. There are, of course, orderly relationships between CS intensity and conditioning effectiveness (e.g., Mackintosh, 1976), but the existence of asymmetries like that reported by James and Wagner suggests that overshadowing is not due just to the intensity or salience of the cue elements; it appears to reflect other, nonassociative mechanisms as well.

The nonassociative mechanism most often invoked to explain overshadowing is attention. It is proposed that, in effect, the animal does not hear the tone because

This work was supported by National Science Foundation Research Grant BNS 80-06038. Reprints are not available. it is looking at the light. It is as if the stimulus elements compete with each other for access to the associative learning machinery. But other devices are also conceivable. For example, perhaps the overshadowed cue, the soft tone, is associated with shock at the time of conditioning, but this association is simply not expressed in behavior at the time of testing. In other words, perhaps the overshadowing phenomenon is due to a failure of retrieval or to response interference, rather than to sensory or associative competition. That is the posbility we sought to test.

The experimental design included a pair of groups to demonstrate overshadowing; one of these groups had light and noise paired with shock ( $\mathrm{LN}+$ ), and the other had noise alone paired with shock $(\mathrm{N}+)$. A third group had light and noise paired with shock but then underwent extinction of fear to the light $(\mathrm{LN}+, \mathrm{L}-)$. What we wanted to demonstrate is that the extinction of fear to the light in this group revives, liberates, or in some way activates the expression of fear to the noise.

\section{METHOD}

\section{Subjects}

The subjects were 36 female rats, 24 of Wistar descent and 12 of Long-Evans descent. They ranged from 90 to 120 days of age. They were individually housed and maintained on a 12:12 light/dark schedule.

\section{Apparatus}

Two boxes were used. One box was $19 \times 23 \times 20 \mathrm{~cm}$, with aluminum sides and Plexiglas front wall, back, and lid. The grid floor consisted of 2-mm stainless steel rods spaced $13 \mathrm{~mm}$ center to center. The second box was $25 \times 26 \times 23 \mathrm{~cm}$, with aluminum sides and back and a Plexiglas front wall. The grid floor consisted of $6-\mathrm{mm}$ stainless steel rods spaced $16 \mathrm{~mm}$ center to center. Each box was housed in a sound-attenuating chamber.

White noise was the auditory stimulus. It was presented through speakers mounted on the ceiling of Chamber 1 and the back wall of Chamber 2. The noise level from each speaker was measured at $71 \mathrm{~dB}$ in the middle of the grid floor. The background noise level was $35 \mathrm{~dB}$. On the rear wall of each chamber was a 7.5-W red light, which remained lit at all times so that the animals could be observed. Both chambers also had a 7.5-W white stimulus light mounted just above the red light, which constituted the visual stimuli. The white lights were operated at reduced input of $40 \mathrm{~V}$. 


\section{Procedure}

The study was run in three replications. To check on the generality of findings, the replications differed in the strain of rats used and the time of day at which they were run. In each replication, the subjects were randomly divided into three groups. All animals received five conditioning trials in one session. Scrambled footshock of $.6-\mathrm{mA}$ intensity and $.5 \mathrm{sec}$ duration was the US. On each conditioning trial, a 30-sec CS was immediately followed by the US. The intertrial interval was fixed at $5 \mathrm{~min}$. The groups differed in the kind of CS presented to them. Two groups received the light and noise paired with shock (LN+), and the third group had only the noise paired with shock $(\mathrm{N}+)$.

The strength of conditioning was not assessed by the usual suppression-of-barpressing measure, but rather, by the suppression of ongoing general activity. During the $30-\mathrm{sec} C S$ and during the preceding $30 \mathrm{sec}$, each animal was observed every $3 \mathrm{sec}$ and was judged to be either active (locomoting, grooming, sniffing, etc.) or freezing (body immobile and none of the vibrissa movement associated with sniffing). Thus, on any trial, an animal could have a CS activity score from 1 to 10 and a pre-CS score from 1 to 10 . The primary data indexing fear of the CS were the differences between pre-CS and CS scores (see Bouton $\&$ Bolles, 1980, for a discussion of this procedure, including its reliability).

Following conditioning, all animals were given two extinction sessions on successive days. For Group N+ and one of the $\mathrm{LN}+$ groups, the extinction experience involved only the extinction of contextual fear, since no CSs were presented. For Group $\mathrm{LN}+, \mathrm{L}-$, the light was presented as it had been during conditioning (i.e., for $30 \mathrm{sec}$ every $5 \mathrm{~min}$ ). Thus, for these animals, there was not only extinction of context fear, but also fear to the light. For all animals, there followed five brief test sessions, each lasting about $6 \mathrm{~min}$. After $5 \mathrm{~min}$ the tone was presented alone for $30 \mathrm{sec}$.

\section{RESULTS}

The suppression of general activity is like the suppression of instrumental activity in that both kinds of behavior tend to be suppressed not only during the CS, but also during the intertrial interval, especially when trials are closely spaced. The difficulty that this loss of baseline can obscure whatever conditioning there may be to the CS was circumvented here by interposing two extinction sessions to reduce context fear and also by the use of a 1-trial/day test procedure. Averaged over all animals and all test trials, freezing constituted only $15 \%$ of the behavior observed during the pre-CS periods (as opposed to 52\% during CS presentations). It should also be noted that there were no differences among groups in mean pre-CS freezing during testing $(\mathrm{F}<1)$.

The test data, shown in Figure 1, demonstrate overshadowing of the noise by the light. Group LN+ showed significantly less suppression of activity than Group N+ $[t(22)=2.86, \quad p<.05]$. The critical comparison between Groups LN+ and LNT,L- to determine if the extinction of fear to the light enchanced fear to the noise was also reliable $[\mathrm{t}(22)=2.83, \mathrm{p}<.05]$. It is interesting that there were no reliable differences among groups on the first test session. We might suppose that when the noise first reappears in the test situation after having been absent for some time, there is a sensitized

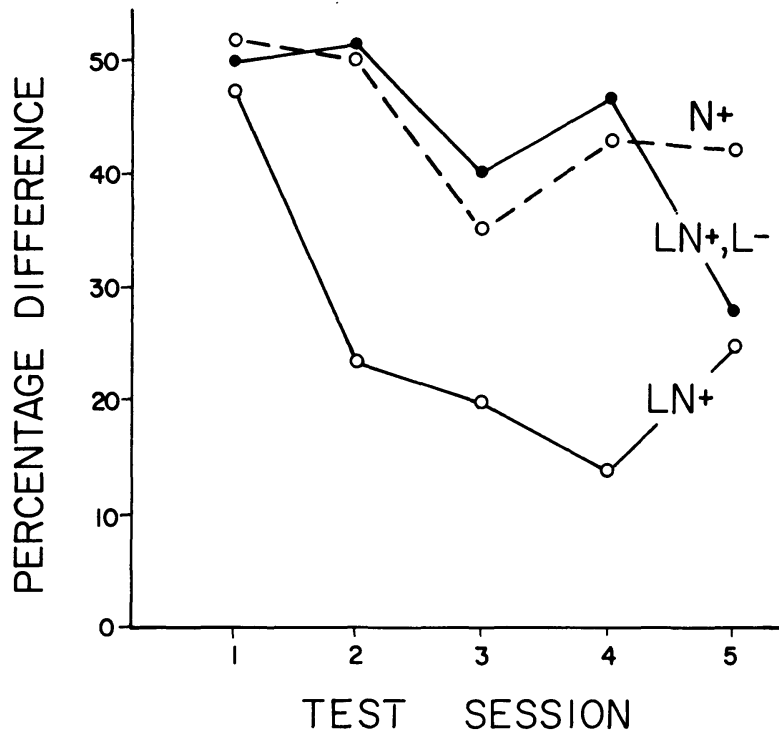

Figure 1. Mean difference in percentage freezing during CS and pre-CS periods. High values imply fear elicited by the noise.

reaction to it that masks the underlying differences among the groups.

\section{DISCUSSION}

If within-compound associations were formed at the time of conditioning (i.e., if the light and noise became mutually associated at the time they occurred together and each of them was becoming associated with the shock to some degree), then one might expect the extinction of fear to the light to diminish whatever fear there might be to the noise. The neutralization of the light should tend, through its association with the noise, to neutralize the noise also. Such an effect has been reported in the conditioned taste aversion literature (Rescorla \& Cunningham, 1978), and indeed, it is just this effect that provides some of the strongest evidence for the concept of within-compound associations. The phenomenon reported here, however, is quite diferent: Neutralization of the light enhanced the signaling power of the noise. It should not be concluded from this finding that within-compound associations may not be formed or cannot be formed in the fear situation; it only says that some other opposing mechanism can be much more important. Nor would we suggest, on the contrary, that there are no real differences in taste aversion conditioning and fear conditioning; many differences are already recognized. We simply lack the data at this time to explain why we find extinction-induced increases in fear of the other cue, whereas Rescorla and Cunningham (1978), using a formally similar procedure, could report extinctioninduced decreases in the aversion of the other cue.

The present results are more like those reported by Lett (in press) in the case of taste potentiation of odor conditioning. She found that following taste-odor compound conditioning, the extinction of the taste aversion failed to reduce the potentiated odor aversion, which was still strong. Albeit these results were obtained under conditions that minimized the possibility of within-compound associations being formed, they still reveal the operation of another mechanism, which we call potentiation, that can outweigh within-compound associations.

It is difficult to accept the idea proposed by Rescorla and 
Wagner (1972) that overshadowing is due to blocking. The idea was that fear to the light goes to asymptote so rapidly that it blocks the conditioning of fear to the noise. One problem with this view is that it fails to recognize that conditioning to the noise may proceed rapidly when the noise alone is the CS. Another problem for the blocking hypothesis is that it cannot explain the occurrence of overshadowing with just one conditioning trial (James \& Wagner, 1980; Mackintosh, 1971). In short, the blocking implication of the model does not appear to locate correctly the source of competition that produces overshadowing.

Another powerful and important implication of the RescorlaWagner model is that contextual conditioning can compete with and limit the conditioning that occurs to a nominal CS. All animals had experienced the same amount of shock in the apparatus prior to testing. The animals in Group $\mathrm{LN}+\mathrm{L}-$ may have experienced somewhat more fear, because fear was repeatedly elicited by the light. According to the RescorlaWagner model, this extra fear (i.e., the extra expectation of shock) in the $\mathrm{LN}+, \mathrm{L}-$ animals should have resulted in somewhat greater extinction of context fear, compared with the other groups, and hence less total fear when the noise was presented in the context at the time of testing. There is no obvious set of assumptions that can be made regarding the various learning rate parameters to account for the enhanced fear of the noise in the group that underwent extinction of the light and context together. It is not clear how the extra fear experienced by this group in extinction could have produced an increment in fear to the noise. Actually, there was no evidence of differential context fear among the groups at the outset of testing. Indeed, there was little evidence of any context fear at the time of the first test-trial testing, since the proportion of freezing was only $4 \%$. Bouton and Bolles (1979) have questioned the validity of such measures of context fear, but for what they are worth (and they are probably worth more with the activity baseline than they are when there is some strong competing behavior, such as barpressing), there was no indication of differential context fear among the groups. So this aspect of the model does not provide a convincing explanation of the finding that extinction of fear to the light enhances the expression of fear to the noise. In spite of its other virtues, the Rescorla-Wagner model seems to mislocate the interference that produces overshadowing.

One of the conventional views of overshadowing regards it as an instance of generalization decrement. The argument is that, for the animal showing the decrement, the stimulus conditions change between conditioning, when the CS compound is present, and testing, when only one element is present. The argument lacks conviction, however, because those experimenters who have controlled for and assessed the amount of generalization decrement in different ways (Mackintosh, 1971; Wagner, 1971) have found that it makes little or no contribution to overshadowing.

The problem, then, is this :If the amount of fear to the noise is not mediated by within-compound association, blocking, or differential context fear, then how was all that noise fear mediated? After considering much of the same evidence that has been discussed here, James and Wagner (1980) concluded that overshadowing is due to selective attention, differential rehearsal, or some such "distributive processing" mechanism. James and Wagner did not distinguish the different possibilities in much detail, but it seems clear that all the possibilities they were considering are well over on the input side of the organism. The processing of stimulus input in some way denies the overshadowed element access to the associative memory mechanism. This is an attractive hypothesis, perhaps because it is basically a generalized form of the familiar selective attention hypothesis. But it is not clear how any interpretation of overshadowing that so emphasizes the stimulus-input phase of processing could deal with the results presented here. How could such an inputoriented interpretation explain a dramatic change in the strength of the noise-shock association following the experimental alteration of the light-shock association?

We suggest a shift in emphasis to the output, responseexpression phase. We propose that both associations are formed at the time of conditioning and that although both associations are present in long-term memory at the time of testing, only one of them, the light-shock association, is expressed in behavior. Specifically, although the rat "knows" that shock follows the noise, this knowledge does not evoke fear responses as long as the animal expects shock to follow the light. When the light-shock expectancy is disconfirmed, the noise-shock association is manifested in behavior. Why the rat should attribute its distress in this situation to the modest light rather than to the loud noise is not clear; perhaps it reflects the animal's tendency to give different kinds of defensive behaviors to different kinds of threats (e.g., Blanchard \& Blanchard, 1971; Sigmundi, Bouton, \& Bolles, 1980). But whatever the details of the process may be, it appears that an important aspect of overshadowing depends upon response-organizing mechanisms that are well over on the output side of the organism.

\section{REFERENCES}

Blanchard, R. J., \& Blanchard, D. C. Defensive reactions in the albino rat. Learning and Motivation, 1971, 2, 351-362.

Bouton, M. E., \& Bolles, R. C. Role of conditioned contextual stimuli in reinstatement of extinguished fear. Journal of Experimental Psychology: Animal Behavior Processes, 1979, 5, 368-378.

Bouton, M. E., \& Bolles, R. C. Conditioned fear assessed by freezing and by the suppression of three different baselines. Animal Learning \& Behavior, 1980, 8, 429-434.

JAmes, J. H., \& WAGNer, A. R. One-trial overshadowing: Evidence of distributive processing. Journal of Experimental Psychology: Animal Behavior Processes, 1980, 6, 188-205.

LETT, B. T. Taste potentiation in poison avoidance learning. Harvard symposium on quantitative analyses of behavior (Vol. 3): Acquisition. New York: Ballinger, in press.

MACKintosh, N. J. An analysis of overshadowing and blocking. Quarterly Journal of Experimental Psychology, 1971, 23, 118-125.

Mackintosh, N. J. The psychology of animal learning. London: Academic Press, 1974.

Mackintosh, N. J. Overshadowing and stimulus intensity. Animal Learning \& Behavior, 1976, 4, 186-192.

Pavlov, I. P. [Conditioned reflexes] (G. V. Anrep, trans.). London: Oxford University Press, 1927.

Rescorla, R. A., \& Cunningham, C. L. Within-compound flavor associations. Journal of Experimental Psychology: Animal Behavior Processes, 1978, 4, 267-275.

Rescorla, R. A., \& Wagner, A. R. A theory of Pavlovian conditioning: Variations in the effectiveness of reinforcement and nonreinforcement. In A. H. Black \& W. F. Prokasy (Eds.), Classical conditioning II: Current research and theory. New York: Appleton-Century-Crofts, 1972.

Sigmundi, R. A., Bouton, M. E., \& Bolles, R. C. Conditioned freezing in the rat as a function of shock intensity and CS modality. Bulletin of the Psychonomic Society, 1980, 15, 254-256.

WAGNer, A. R. Elementary associations. In H. H. Kendler \& J. T. Spence (Eds.), Essays in neo-behaviorism: A memorial volume to Kenneth $W$. Spence. New York: Appleton-CenturyCrofts, 1971.

(Received for publication October 1, 1981.) 